\title{
RELATIONSHIP OF \\ EUGENOLATE FORMATION TO THE SETTING MECHANISM OF ZINC OXIDE EUGENOL CEMENTS
}

\author{
By: Hamdi Mohammed, D.D.S., M.Sc.D., Ph.D., F.I.C.D.
}

\author{
*College of Dentistry, University of Florida, \\ Gainesville, Florida 32610
}

In Dentistry, a mixture of eugenol liquid (extract of oil of cloves) and zinc oxide powder enjoys many favored uses. The mixture is used as an obtunding temporary filling material, for temporarily cementing dental inlays, crowns and bridges, for endodontic treatment and for taking impressions of edentulous cases. Despite this popularity of the material and its significance in dentistry, the hardening or setting mechanism of the material is not fully understood.

Review of the literature ${ }^{1-6}$ indicates that the major problem with respect to the setting of zinc oxideeugenol (ZOE) cement is whether zinc eugenolate crystals form as a result of the setting reaction and whether their formation causes the setting of the mix. The studies that dealt with the acceleration of $\mathrm{ZOE}^{7-11}$ showed no systematic work to study the effect of an accelerator on the setting time of ZOE. The accelerator's efficiency was referred to its cation by some investigators ${ }^{11}$ and to its anion ${ }^{3}$ by others.

The purpose of this investigation was to study the effect of several accelerators when used in a powder form and as eugenol solutions on the setting time of $\mathrm{ZOE}$; to study the relationship between the time of formation of eugenolate crystals and the setting time of $\mathrm{ZOE}$; to illustrate whether the acceleration of $\mathrm{ZOE}$ is cationic or anionic in nature; and to study the effect of accelerator concentration ${ }^{12}$ and eugenolate concentration on the compressive strength of ZOE.

\section{Materials and Methods}

Zinc acetate*, zinc propionate*, silver acetate ${ }^{* *}$, and glacial acetic acid ${ }^{* * *}$ were used as accelerators for standard mixes of zinc oxide $* \cdots *$ and eugenol*. The powder accelerators were either added to zinc oxide before the addition of eugenol or were dissolved in eugenol before mixing with zinc oxide. Acetic acid was either added to a partially mixed ZOE or was dissolved first in eugenol. Setting times were determined by Kreb's penetrometer. Compressive strength samples that contained powder accelerator were kept in their molds in a $100 \%$ relative humidity. All compression samples were tested after
72 hours from the start of mixing. Saturated solutions***** of zinc acetate and silver acetate in eugenol were prepared. The dissolution of these solids and zinc oxide in eugenol resulted in the formation of a new phase. Since the time of stirring that was necessary to dissolve a saturation concentration of an accelerator in eugenol and that at which the new phase form, were two overlapping processes, dilute solutions were prepared and left to stand. The time at which precipitation took place was recorded. All reported results consist of the means of 5 replications at each instance together with the appropriate $68 \%$ confidence interval estimate.

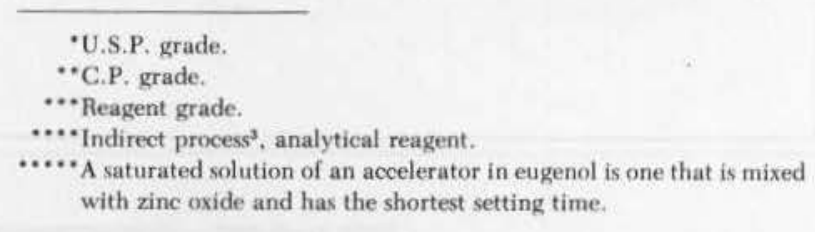

Results and Discussion

The initial and final setting times $\uparrow$ of unaccelerated $\mathrm{ZOE}$ under the experimental environment were 38 and 54 hours, respectively. When the accelerator was used in a powder form (Figure 1) the setting times of $\mathrm{ZOE}$ decreased as the concentration of the accelerator increased. This relationship was not linear. The efficiency of a given amount of an accelerator decreased as its total concentration in the mix increased to a point where any additional increase in the accelerator concentration will have no influence on the setting time of $\mathrm{ZOE}$. It should be noticed

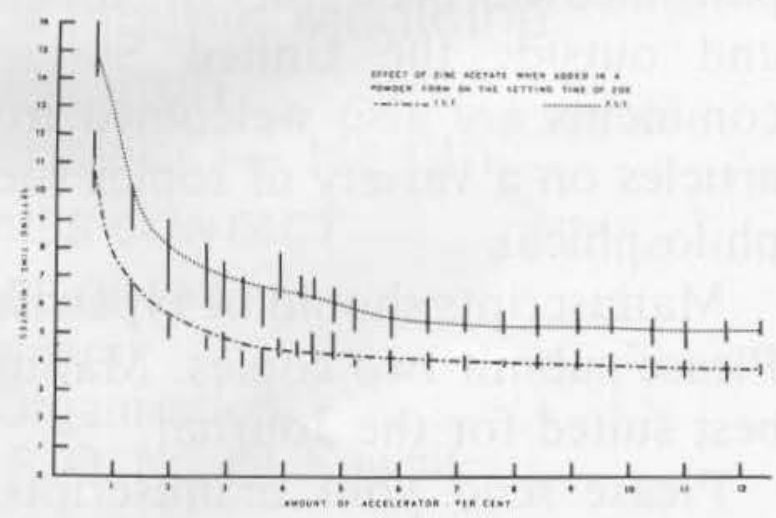

Figure 1: Effect of zinc acetate when used in a powder form on the setting times of ZOE. 


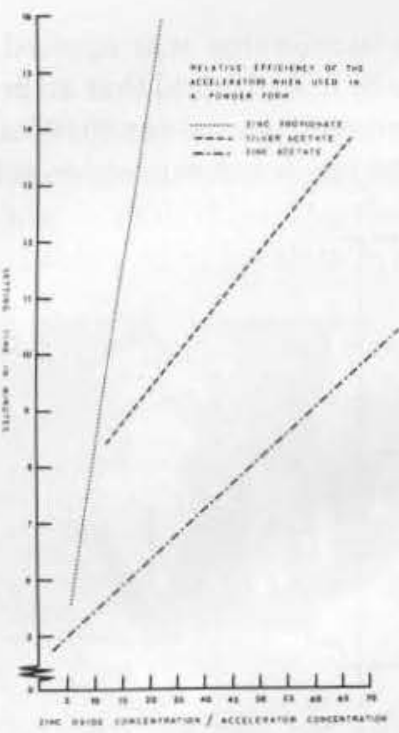

Figure 2: Relative efficiency of three accelerators when used in a powder form.

that a final setting of 6 minutes was produced when $5.5 \%$ zinc acetate was used. Any given accelerator concentration has more influence on the F.S.T. $\uparrow$ than on the I.S.T. as evidenced by the consistent decrease in the setting reaction period (period of time lapses between I.S.T, and F.S.T.)

The relative efficiencies of the three powder accelerators used are illustrated in Figure 2. The smaller the slope of the setting time - accelerator concentration curve, the higher the efficiency of the accelerator. In a decreasing order the accelerators can be classified as zinc acetates, silver acetate and zinc propionate. Glacial acetic acid was more efficient than zinc acetate.

The saturation concentrations for zinc acetate, silver acetate, and acetic acid in eugenol were 1.35, 1.85 , and $0.589 \%$, respectively. An accelerator concentration of $1.35 \%$ in eugenol is equivalent to a concentration of $0.35 \%$ in ZOE. Comparison of Figure 1 to Figure 3 shows that a final setting time of 6 minutes was obtained when $0.18 \%$ accelerator was applied as eugenol solution. This indicates that the accelerator efficiency can be increased more than 20 times if it is applied as eugenol solution. The same applied for silver acetate.

The increase in an accelerator efficiency when dissolved in eugenol is due to the fact that the accelerator is more or less dissociated in eugenol and its ions are available for the setting reaction. When applied in a powder form only the surface of the particles should be attacked by the eugenol. It was found that for a given accelerator concentration, the smaller the particle size of the accelerator, i.e. the larger the accelerator surface area exposed to eugenol, the more efficient it is.

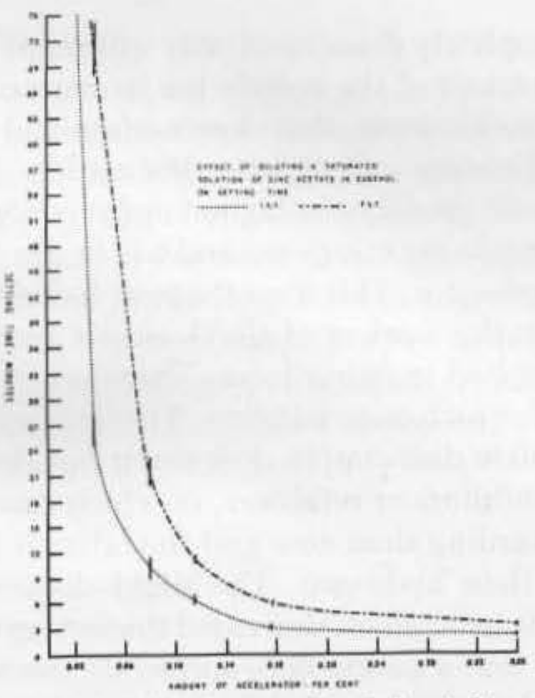

Figure 3: Effect of diluting a saturated solution of zinc acetate in eugenol on the setting times of ZOE.

The accelerating efficiency of zinc acetate and silver acetate as eugenol solutions is higher, about 1.3 times, if they were used before the precipitation of the reaction product. This is because some of the accelerator cations will react with eugenol to produce eugenolate. The loss of these ions decrease the efficiency of the solution. A more illustrative condition is when zinc oxide, which is slightly soluble in eugenol, was stirred in eugenol. When this solution was mixed with zinc oxide to form a mix of a clinical consistency, it sets in 12 hours. If the same solution is left to stand until all the reaction product precipitated then mixed with zinc oxide, it sets in 54 hours. This indicates that all the zinc ions in this case reacted with eugenol and precipitated.

The percent of zinc or silver ion that react with eugenol and precipitate from their appropriate accelerator solutions in eugenol was found to be less than $5 \%$ of the total cation concentration. Assuming $100 \%$ dissociation this indicates that more than $95 \%$ of the cation and $100 \%$ of the anion stay indefinitely in eugenol. The dissociation, however, is not complete (Figure 4). If the saturation concentrations of the 3 acetate accelerators in eugenol have

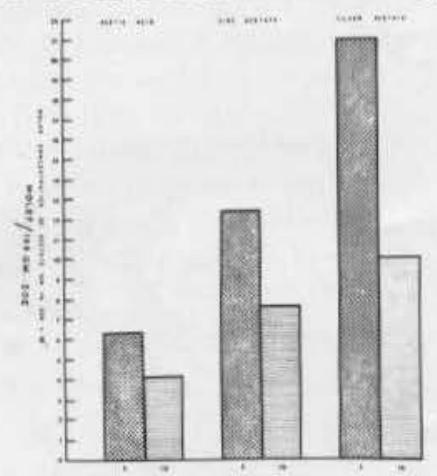

Figure 4: Molar concentrations of the acetate ion in 3 ace tate accelerators. (Assuming $100 \%$ dissociation of saturation concentrations.) 
been completely dissociated, this will result in Molar concentrations of the acetate ion in eugenol, for the various accelerators, that does not explain their relative efficiency. Complete dissociation of silver acetate will produce the highest molar concentration of the acetate ion in eugenol and will be the most efficient accelerator. This is not the case, however. Silver acetate is the weakest of the 3 acetate accelerators, when applied in either form. There are two explanations for such contradiction. The first explanation is; complete dissociation does occur but the cations act as inhibitors or retarders, in which case silver is more retarding than zinc and the latter is more retarding than hydrogen. The slight dissociation of zinc oxide in eugenol, decreased the setting time, indicating that a cation does accelerate the setting of $\mathrm{ZOE}$ and its efficiency is dependent on its parent salt solubility in eugenol. This antagonizes the above explanation. The only explanation that is left now, is that the dissociation of the saturation concentrations of silver acetate and zinc acetate in eugenol was not complete.

When any accelerator concentration was dissolved in eugenol and left to stand floculation did not appear before the lapse of 7 hours from the start of mixing and continued for 24 hours. This indicates that the formation of eugenolate crystals occur after the setting of ZOE and hence the former can't predetermine the latter. Once floculation was completed and removed from the solution, the solution accelerator efficiency stays constant. This was determined by using these solutions 6 months after their preparation.

The floculent (Figure 5) possesses the characteristics of eugenolates of the appropriate cation according to Copeland ${ }^{1}$, et al.

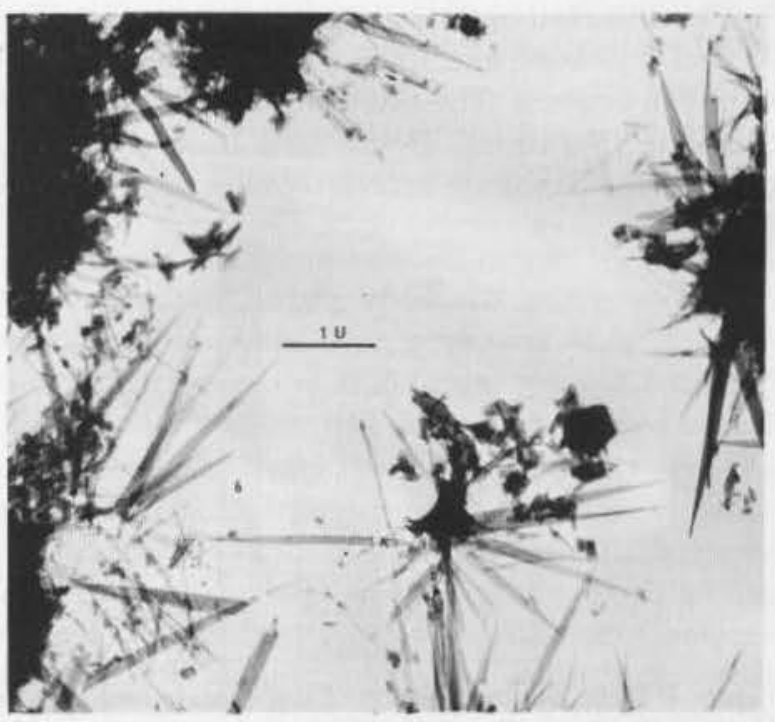

Figure 5: Electron photomicrograph of pure zinc eugenolate.
When the accelerator was applied in a powder form (Figure 6) it was found that an accelerated mix of $\mathrm{ZOE}$ is stronger than a non accelerated one provided that the mix is not exposed to water.

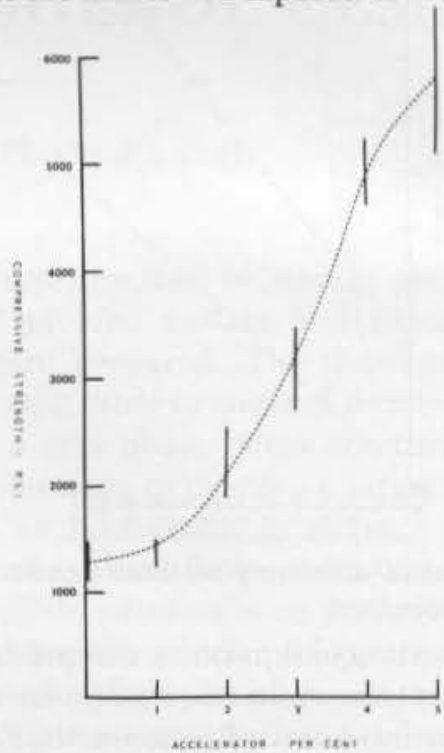

Figure 6: Effect of zinc acetate concentration on the com. pressive strength of ZOE.

When the accelerator was applied as eugenol solution, the compressive strength was not improved. The presence of zinc acetate particles in $\mathrm{ZOE}$ and in contact with eugenol results in the formation of some eugenolate crystals (about $5 \%) \ddagger$ which will act as a framework for the mix and increase its compressive strength. When the accelerator is used as eugenol solution, the only eugenolate crystals that may form are those resulting from the reaction between zinc oxide and eugenol. Since zinc oxide is scarcely soluble in eugenol, there will practically be no eugenolate formation or may be less than $1 \%$.

The addition of various quantities of zinc eugenolate to ZOE (Figure 7) improved the compressive

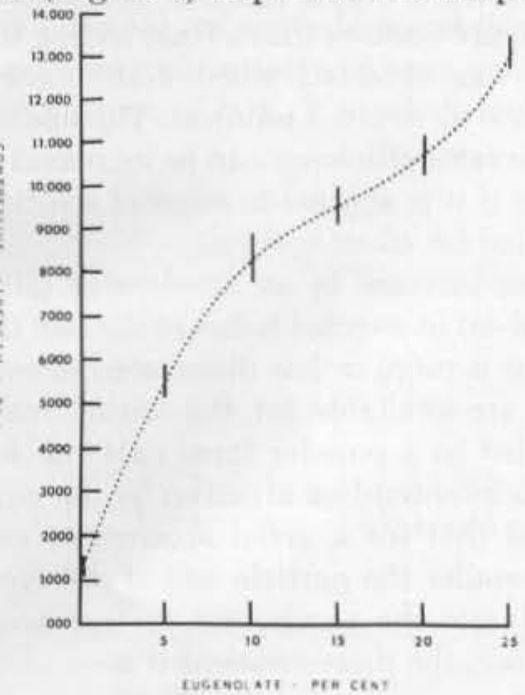

Figure 7: Effect of zinc-eugenolate concentration on the compressive strength of $\mathrm{ZOE}$. 
strength up to 13126 psi for a mix that contains $25 \%$ eugenolate. Electron photomicrograph (Figure 8) of $25 \%$ eugenolate - ZOE illustrates the relationship between zinc oxide and eugenolate cyrstals.

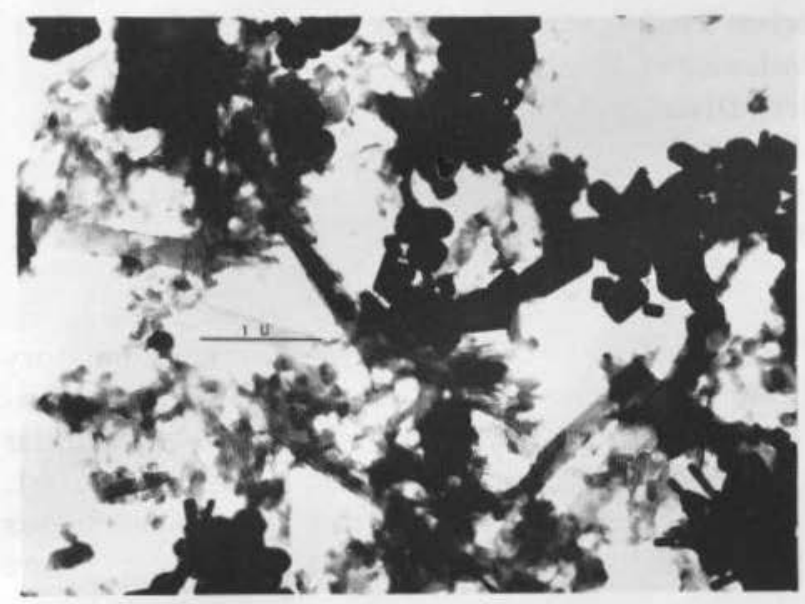

Figure 8: Electron photomicrograph of $25 \%$ eugenolate ZOE mix.

\section{Summary and Conclusions}

The accelerating efficiency of 3 powders and one liquid accelerator on the setting times of $\mathrm{ZOE}$ was studied. The accelerators were applied in two forms, as powders and as eugenol solutions. When any of the powder accelerators or zinc oxide were dissolved in eugenol to form a clear solution and left to stand, eugenolates of the appropriate cations were precipitated. The precipitation of eugenolate crystals from the solution did not occur before the lapse of at least 7 hours from the start of mixing. The effects of the accelerator concentration and eugenolate concentration on the compressive strength of $\mathrm{ZOE}$ was also studied. The following conclusions were made.

1. The setting of ZOE decreases as the accelerator concentration increase within practical limits.

2 . The concentration of any accelerator that produces a given setting time can be reduced to less than $5 \%$ if the accelerator is applied as eugenol solution.

3. The acceleration of ZOE is due to the dissociation of the accelerator in eugenol. It is the presence of free ions in eugenol, whether anions or cations that causes the acceleration.
4. The higher the dissociation of a given material in eugenol, the higher will be its accelerating efficiency, taking in consideration the ion strength.

5. The reaction between zinc oxide and eugenol may result in the formation of eugenolate. This reaction however occurs far after setting of $\mathrm{ZOE}$.

6. The incorporation of eugenolate crystals or their production in $\mathrm{ZOE}$ mixes improve the compressive strength of the cement.

\By comparison to Figure 7.

\section{Bibliography}

1. Copeland HI, Brauer GM, Sweeney WT, and Forziati AF: Setting Reaction of Zine Oxide and Eugenol. J Res Nat Bur Stand 1955; 55:133-138.

2. Brauer GM, White EE Jr, and Mashonan MG: The Reaction of Metal Oxides with O-Ethoxybenzeoic Acid and Other Chelating Agents. J Dent Res 1958; 37:547-560.

3. Smith DC: The Setting of Zine Oxide and Eugenol Mixtures. Brit DJ 1958; 105:313-321.

4. Viellefosse R, Vayson de P, and Zumbrunn JP: A Study of Combination of Types of Oxides of Zinc-Eugenol Cement and Phenol Plastics. Rev Frac Odonto Stomatol 1958; 5:488-494.

5. Grant AA, Greener EH and Meshii M: High Resolution Microscopy of Dental Cements. 6th International Congress for Electron Microscopy, Kyoto, Japan, 1966.

6. Brauer GM: A Review of Zinc Oxide-Eugenol Filling Materials and Cements. Rev Blege Med Dent Bleg Tijds Vr Tandheelk 1965; Vol. 20 No. 3:323-364.

7. Howe, PR: The Conservation of the Dental Pulp. Dental Items of Interest 1919; 41-933-939.

8. Ross, RA: Zine Oxide Impression Pastes. J Am Dent Assn 1934: 21:2029-32.

9. Crowell WS: U.S. Patent 2,406,063, August 20, 1936.

10. Wallace DA and Hensen HL: Zinc Oxide Eugenol Cements. J Am Dent Assn 1939: 26-1536-1540.

11. Molnar EJ and Skinner EW: A Study of Zinc Oxide-Rosin Cements. 1. Some variables which affect the hardening time. J Am Dent Assn 1942; 29-744-751.

12. Paffenbarger GC and Caul HJ: Zine Oxide-Eugenol Cement. Proc Dent Cent Celebration 1940: 232-237. 